
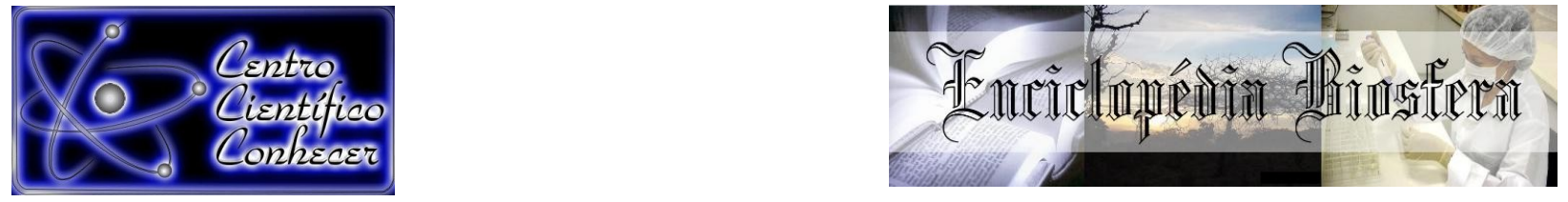

\title{
TENDÊNCIAS CLIMÁTICAS NA MESORREGIÃO DA MATA PARAIBANA E SUA INFLUÊNCIA NA PRODUÇÃO DE ENERGIA FOTOVOLTAICA
}

Louise Pereira da Silva1, Susane Eterna Leite ${ }^{2}$, Wallysson Klebson de Medeiros Silva $^{3}$, Raphael Abrahão ${ }^{4}$

${ }^{1}$ Graduanda em Engenharia de Energia Renováveis da Universidade Federal da Paraíba, João Pessoa, Brasil.

${ }^{2}$ Mestre em Engenharia de Energia Renováveis da Universidade Federal da

Paraíba, João Pessoa, Brasil.

${ }^{3}$ Mestrando em Engenharia de Energia Renováveis da Universidade Federal da Paraíba, João Pessoa, PB, Brasil.

${ }^{4}$ Doutor, professor do Departamento de Engenharia de Energias Renováveis da Universidade Federal da Paraíba, João Pessoa, Brasil (raphael@cear.ufpb.br).

Recebido em: 06/04/2018 - Aprovado em: 10/06/2018 - Publicado em: 20/06/2018 DOI: 10.18677/EnciBio_2018A118

\begin{abstract}
RESUMO
As mudanças climáticas podem ser prejudiciais para todos os setores da sociedade, com possíveis impactos ambientais negativos permanentes, como por exemplo, a extinção de diferentes espécies de um ecossistema. Os seres vivos normalmente necessitam de um período de adaptação para criar mecanismos de sobrevivência ao novo clima. A produção de energia segue um padrão similar, principalmente para fontes renováveis, que estão estritamente relacionadas com o clima local. Neste trabalho, dados climáticos da mesorregião da Mata Paraibana foram analisados para a caracterização climática e a compreensão das tendências nos parâmetros temperatura máxima, mínima e média, além da nebulosidade. A evolução desses elementos climáticos na mesorregião foi avaliada para verificação da estimativa de produção de eletricidade utilizando dois modelos de painéis fotovoltaicos empregados comercialmente no Brasil. Desta forma foi possível mensurar impactos das mudanças climáticas no desempenho dos painéis fotovoltaicos.
\end{abstract}

PALAVRAS-CHAVE: Energia solar, Mudança climática, Temperatura.

\section{CLIMATE TRENDS IN THE MATA PARAIBANA MESOREGION AND ITS INFLUENCE IN THE PRODUCTION OF PHOTOVOLTAIC ENERGY}

\begin{abstract}
Climate change can be damaging to all sectors of society, with possible permanent negative environmental impacts such as the extinction of different species from an ecosystem. Living things usually require an adaptation period to create mechanisms for survival to the new climate. Energy production follows a similar pattern, especially for renewable sources, which are closely related to the local climate. In this study, climatic data from the Mata Paraibana mesoregion were analyzed for the climatic characterization and understanding of trends in the parameters maximum, minimum and mean temperature, besides cloudiness. The evolution of these parameters in the mesoregion was understood to verify the estimation of electricity production for two
\end{abstract}


models of photovoltaic panels. In this way, impacts of climate change on the performance of the photovoltaic panels were measured.

KEYWORDS: Climate change, Solar energy, Temperature.

\section{INTRODUÇÃO}

As mudanças climáticas podem produzir diversos impactos ambientais negativos, desequilibrando muitos ecossistemas. As diferentes formas de vida existem em razão de uma série de lentas adaptações ao clima e ao ambiente, contudo, mudanças repentinas podem levar à extinção de diversas espécies, diminuindo a biodiversidade da Terra. Mudanças climáticas mais intensas foram observadas após o aumento da atividade industrial, com a utilização excessiva de combustíveis fósseis. Os danos ambientais foram severos, com elevações dos níveis de poluição sólida, líquida e gasosa (IPCC, 2014).

O setor energético está entre os que mais têm recebido críticas relacionadas aos níveis de emissões de gases de efeito estufa. A queima de combustíveis de origem fóssil pode emitir quantidades exorbitantes de dióxido de carbono, metano e óxido nitroso, agravando o aquecimento global (ROMANO, 2014; IPCC, 2014). Fontes alternativas de geração de energia, como a energia solar, a energia eólica e a energia hidráulica, estão sendo implementadas para suprir a crescente demanda energética através de métodos mais eficientes e sustentáveis. A diversificação na matriz energética torna o sistema mais seguro e confiável, sendo possível implantar tecnologias para compensar a sazonalidade dos recursos, mantendo a oferta de energia mais constante e sem se submeter às pressões de insumos, matéria prima, capital, dentre outros (FOLEY; OLABI, 2017).

Vale salientar que mesmo a geração de energia utilizando fontes renováveis pode gerar impactos ambientais negativos. Além disso, as mudanças climáticas podem afetar as produções energéticas renováveis. Por exemplo, mudanças na velocidade do vento sensibilizarão a produção de energia eólica em uma área específica afetada por essas mudanças; e alterações no regime de chuvas influencia o desempenho das hidrelétricas (SIQUEIRA, 2011). A matriz energética do Brasil é predominantemente de fonte renovável, com uma grande parte de sua produção tendo origem em fontes de recursos hídricos (eletricidade) e de biomassa (transporte) (PORTAL BRASIL, 2014; BRASIL, 2016).

A energia solar é oriunda de fonte renovável e sustentável, podendo ser empregada para aquecimento de fluidos ou produção de eletricidade em diferentes regiões do planeta. Latitudes inferiores a $30^{\circ}$ (locais próximos à linha do Equador) recebem cinco vezes mais energia solar do que latitudes superiores a $60^{\circ}$ (CONTI, 2005; SANTIAGO et al., 2018).

Utilizando painéis fotovoltaicos (células fotovoltaicas) a radiação solar é convertida em eletricidade. Para a correta e mais eficiente produção fotovoltaica é fundamental a compreensão do clima local e regional, pois os elementos climáticos encontrados implicarão nos valores produzidos (SIQUEIRA, 2011; CARVALHO; DELGADO, 2017). Além disso, a compreensão de mudanças climáticas através desses elementos é tão importante quanto a caracterização do clima, uma vez que pode auxiliar o desenvolvimento tecnológico e a preferência de tecnologias para produção e uso de energia. Este trabalho teve o objetivo de avaliar as mudanças climáticas na mesorregião da Mata Paraibana, analisando possíveis consequências dessas mudanças na produção elétrica fotovoltaica. 


\section{MATERIAL E MÉTODOS}

A área de estudo escolhida foi a mesorregião da Mata Paraibana. O estado da Paraíba está localizado na região Nordeste do Brasil e divide-se em quatro mesorregiões: Sertão Paraibano, Borborema, Agreste Paraibano e Mata Paraibana. A mesorregião da Mata Paraibana é subdivida em Litoral Norte, Sapé, João Pessoa e Litoral Sul e o bioma característico dessa mesorregião é a Mata Atlântica (IBGE, 2010).

Os dados utilizados foram disponibilizados pelo Instituto Nacional de Meteorologia (INMET). Foram utilizados dados da estação convencional (código OMM 82798) e da estação automática (código OMM 81918) pertencentes à cidade de João Pessoa (Paraíba), capital do estado da Paraíba. Foram coletados dados mensais e diários referentes ao período entre janeiro de 1961 e dezembro de 2014.

Os parâmetros selecionados foram temperatura média, temperatura máxima, temperatura mínima e nebulosidade. Para a medição dos parâmetros foram utilizados instrumentos meteorológicos padronizados pelo INMET e os dados de nebulosidade foram obtidos a partir de observação direta, sem instrumentos. Para a obtenção da temperatura média o INMET aplica a equação 1 , referente à temperatura média compensada.

$$
T_{M C}=\frac{T_{\max }+T_{\min }+T_{12 U C}+2 T_{24 U C}}{5}
$$

Onde $T_{M C}=$ Temperatura média, $T_{\text {máx }}=$ Temperatura máxima registrada, $T_{\text {min }}$ = Temperatura mínima registrada, $T_{12 U C}=$ Temperatura registrada às 12 UTC (Tempo Universal Coordenado) e $\mathrm{T}_{24 U \mathrm{c}}=$ Temperatura registrada às 24 UTC.

Os dados na sua forma integral foram organizados por parâmetro em planilhas e, em seguida, foram submetidos a um processo de controle de qualidade para verificação e eliminação de erros derivados de problemas técnicos ou de transmissão dos dados.

Para a caracterização climática, cada parâmetro foi submetido a uma média dos dados mensais, ou seja, valores que representam o mês médio no período 1961-2014 (normal climatológica). Dessa forma, foi possível a construção de gráficos similares a climatogramas para os parâmetros selecionados, representando valores de normais mensais ao longo de todo o ano (MENDONÇA; DANNIOLIVEIRA, 2007).

O teste de Mann-Kendall foi utilizado nas analises estatísticas de tendências, pois este método permite o estudo de funções monótonas, ou seja, examina se os dados estão atuando de forma crescente ou decrescente. A tendência linear foi avaliada através do método de Sen (SALMI et al., 2002). No método de Sen o modelo linear é utilizado para estabelecer a amplitude da tendência e a variação dos dados ao longo do tempo (SALMI et al., 2002).

Foram selecionados dois modelos de painel fotovoltaico: AXITEC AC-270P/156-60S, com eficiência de conversão de $16,6 \%$, potência nominal de $270 \mathrm{Wp}$ e área de 1,63 $\mathrm{m}^{2}$ (AXITEC, 2016); e Panasonic VBHN240SJ25, com eficiência de conversão de 19,0\%, potência nominal de $240 \mathrm{Wp}$ e área de 1,26 m² 
(PANASONIC, 2017). Os cálculos foram realizados considerando 100 painéis de cada modelo e a potência $(P)$ gerada pelo sistema foi dada pela equação 2 (AXITEC, 2016).

$$
P=N P I \cdot A \cdot e f f \cdot\left(\frac{G(t)}{1000}\right) \cdot f_{t e m p}
$$

Em que o ${ }^{N P I}$ é o numero de painéis instalados, ${ }^{A}$ corresponde à área do painel, ${ }^{e f f}$ é a eficiência do painel fotovoltaico, ${ }^{G(t)}$ é a irradiação solar $\left(\mathrm{W} / \mathrm{m}^{2}\right)$, e

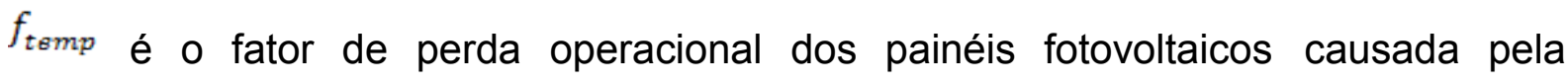
temperatura. A varíavel $f_{t e m p}$ pode ser definida pela equação 3 (NOTTON et al., 2005).

$$
f_{t \theta m p}=\left[1-\beta^{\prime}\left(\theta_{c \theta l l}-\theta_{c \theta l l, r \theta f}\right)+\gamma \log \left(\frac{G_{\beta}}{G_{\beta, r \theta f}}\right)\right]
$$

Sendo $\beta^{\prime}$ o coeficiente de potência de temperatura $\left({ }^{\circ} \mathrm{C}^{-1}\right)$, $\theta_{\text {csll }}$ a

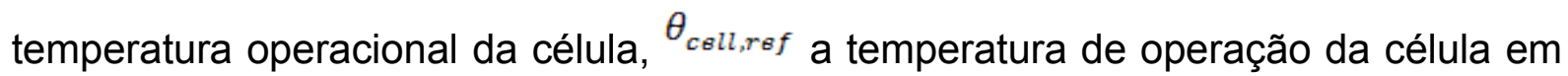
condições de teste padrão, ${ }^{\gamma}$ o coeficiente da irradiação solar, ${ }^{G_{\beta}}\left(\mathrm{W} / \mathrm{m}^{2}\right)$ é a irradiação solar nos painéis fotovoltaicos, e $e_{\beta, r \text {, }}^{G_{\text {f }}}\left(\mathrm{W} / \mathrm{m}^{2}\right)$ é a irradiação solar em condições de teste padrão. Os valores utilizados para as variáveis da equação 3 para um painel fotovoltaico de silício foram $\beta^{\prime}=0,0042{ }^{\circ} \mathrm{C}^{-1}, \theta_{\text {cell,ref }}=25{ }^{\circ} \mathrm{C}$, $\gamma=0.12$, e $G_{\beta, r \theta f}=800 \mathrm{~W} / \mathrm{m}^{2}$. $\theta_{\text {cell }}$ pode ser definido através da equação 4 (AKHSASSI et al., 2018).

$$
\theta_{\text {coll }}=\theta_{a}+(N O C T-20) \cdot\left(\frac{G_{\beta}}{800}\right)
$$

Em que $\theta_{a}$ corresponde à temperatura ambiente $\left({ }^{\circ} \mathrm{C}\right)$ e ${ }^{N O C T}$ é a temperatura nominal de operação da célula $\left({ }^{\circ} \mathrm{C}\right)$, estabelecido pelo fabricante em $45^{\circ} \mathrm{C}$.

A produção fotovoltaica foi estimada para os dois modelos de painel durante os dez primeiros anos da série de dados climáticos, os dez últimos anos e a série completa. 


\section{RESULTADOS E DISCUSSÃO}

\section{Caracterização da área de estudo}

As temperaturas médias mensais variam pouco ao longo do ano, com valores próximos a $25,0{ }^{\circ} \mathrm{C}$ nos meses de inverno e próximos a $28,0^{\circ} \mathrm{C}$ no verão. De novembro a abril as temperaturas máximas são elevadas, oscilando entre $29,0^{\circ} \mathrm{C}$ e $30,7^{\circ} \mathrm{C}$, e de junho a agosto as temperaturas mínimas ficam um pouco abaixo de $22,0^{\circ} \mathrm{C}$. A variação de nebulosidade também é pequena ao longo do ano, com valores sensivelmente mais elevados durante os meses de inverno (Fig. 1).

As características observadas na estação meteorológica de João Pessoa são representativas da mesorregião da Mata Paraibana, típicas do tipo climático "tropical litorâneo do Nordeste oriental" (classificação de Strahler adaptada pelo IBGE).
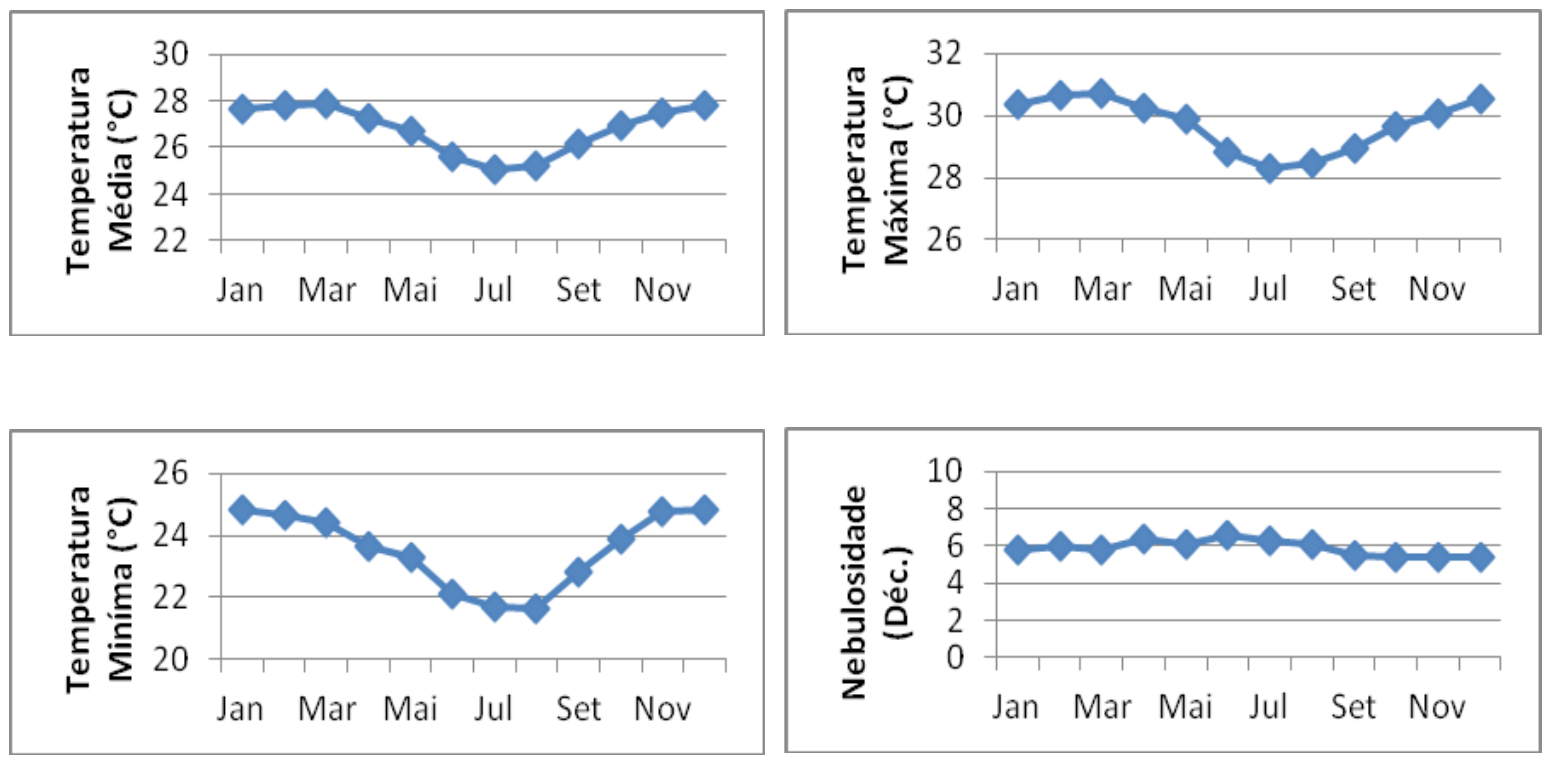

FIGURA 1. Caracterização climática (normais climatológicas) da temperatura média, temperatura máxima, temperatura mínima e nebulosidade para a cidade de João Pessoa (1961-2014).

\section{Tendências climáticas observadas}

As tendências anuais observadas para as temperaturas máxima, média e mínima foram expressivas ( $p<0,001$ nos três casos) (Tab. 1), confirmando a interação dos dados e o crescimento relevante desses três parâmetros relacionados à temperatura durante o período analisado. Para as temperaturas máxima e mínima, todos os meses apresentaram tendências significativas ( $p<0,001$ ou $p<0,01)$, com tendência de aumento das temperaturas em todos os casos. Para a temperatura média, em alguns meses observou-se menor significância estatística (principalmente junho e agosto). Ainda assim, em todas as séries mensais constatou-se que houve aumento nas temperaturas.

Esses resultados estão de acordo com diversos estudos (MARENGO; CAMARGO, 2007; GIRVETZ, 2009; DJAMAN et al., 2016), que constataram 
tendências de aumentos significativos de temperatura do ar no sul do Brasil, nos países do hemisfério norte e no Senegal, respectivamente. O aumento da temperatura da Terra é um tema científico cada vez mais preocupante. As três últimas décadas foram as mais quentes desde 1850 e o aumento na temperatura média global foi de aproximadamente $0,85^{\circ} \mathrm{C}$ no período de 1880 a 2012 (IPCC, 2014).

Para os dados de nebulosidade, não houve tendência anual significativa. Contudo, em alguns meses foi detectado aumento significativo dos valores (janeiro, fevereiro e dezembro). É interessante observar que esse aumento significativo da nebulosidade na área ocorreu principalmente nos meses de verão. 
TABELA 1. Tendências detectadas nos dados de temperatura máxima, temperatura mínima, temperatura média e nebulosidade através do teste de Mann-Kendall, quantificadas pelo declive Sen, para João Pessoa (Paraíba), entre os anos de 1961 e 2014.

\begin{tabular}{lcccc}
\hline Período & $\begin{array}{c}\text { Temperatur } \\
\text { a máxima } \\
\left({ }^{\circ} \mathbf{C} / \text { ano) }\right.\end{array}$ & $\begin{array}{c}\text { Temperatur } \\
\text { a mínima } \\
\left({ }^{\circ} \mathbf{C} / \text { ano) }\right.\end{array}$ & $\begin{array}{c}\text { Temperatur } \\
\text { a média } \\
\left({ }^{\circ} \mathbf{C} / \text { ano) }\right.\end{array}$ & $\begin{array}{c}\text { Nebulosidade } \\
\text { (décimos/ano) }\end{array}$ \\
\hline Janeiro & $0,03^{* * *}$ & $0,07^{* * *}$ & $0,03^{* *}$ & $0,03^{*}$ \\
Fevereiro & $0,04^{* * *}$ & $0,07^{* * *}$ & $0,04^{* * *}$ & $0,02+$ \\
Março & $0,04^{* * *}$ & $0,08^{* * *}$ & $0,06^{* * *}$ & $-0,01 \mathrm{~ns}$ \\
Abril & $0,04^{* * *}$ & $0,06^{* * *}$ & $0,05^{* * *}$ & - \\
Maio & $0,04^{* * *}$ & $0,05^{* * *}$ & $0,03^{* *}$ & $0,02 \mathrm{~ns}$ \\
Junho & $0,03^{* *}$ & $0,04^{* * *}$ & $0,02+$ & $0,01 \mathrm{~ns}$ \\
Julho & $0,05^{* * *}$ & $0,05^{* * *}$ & $0,03^{* *}$ & $0,02 \mathrm{~ns}$ \\
Agosto & $0,05^{* * *}$ & $0,05^{* * *}$ & $0,03+$ & $0,02 \mathrm{~ns}$ \\
Setembro & $0,04^{* * *}$ & $0,06^{* * *}$ & $0,03^{*}$ & $0,01 \mathrm{~ns}$ \\
Outubro & $0,03^{* * *}$ & $0,07^{* * *}$ & $0,04^{* * *}$ & $0,02 \mathrm{~ns}$ \\
Novembro & $0,03^{* * *}$ & $0,07^{* * *}$ & $0,04^{* * *}$ & $0,01 \mathrm{~ns}$ \\
Dezembro & $0,03^{* * *}$ & $0,06^{* * *}$ & $0,03^{* * *}$ & $0,03^{*}$ \\
Anual & $0,04^{* * *}$ & $0,06^{* * *}$ & $0,04^{* * *}$ & $0,01 \mathrm{~ns}$ \\
\hline ns = não significativo; $+p<0,10 ;{ }^{*} p<0,05 ;{ }^{* *} p<0,01 ;{ }^{* *} \mathrm{p}<0,001 ;-=$ não conclusivo
\end{tabular}

\section{Avaliação da influência das tendências climáticas na produção fotovoltaica}

Normalmente, os módulos fotovoltaicos operam em condições distintas das condições de padrão do sistema, tendo suas grandezas elétricas alteradas com variações da irradiância e da temperatura do ar (HECKTHEUER, 2001). A eficiência de um painel fotovoltaico está relacionada, entre outras coisas, com a temperatura de operação das células fotovoltaicas, ou seja, se a temperatura do módulo for muito alta a eficiência poderá ser reduzida.

A produção de energia elétrica apresentou diminuição na comparação dos dez primeiros anos com os dez últimos anos da série climática, reforçando o conceito da influência da temperatura no desempenho dos painéis fotovoltaicos (Tab. 2 e Tab. 3).

No caso do presente estudo, os aumentos observados na temperatura do ar na mesorregião da Mata Paraibana provocaram aumentos na temperatura das células fotovoltaicas, reduzindo assim a produção de energia elétrica. Contudo, essa redução foi muito pequena, representando menos de $1 \%$ nos valores anuais e podendo ser ligeiramente superior somente em alguns meses do ano.

A produção de energia elétrica foi maior utilizando o modelo AC-270P/156-60S da AXITEC, simplesmente porque a área desse modelo é maior. Ao longo do ano, a geração de eletricidade apresentou valores mais elevados a partir do mês de agosto, sendo os picos de produção em outubro, acima de $4700 \mathrm{KWh} / \mathrm{mês}$. De abril a julho a produção foi menor, chegando a menos de $3200 \mathrm{KWh} / \mathrm{mês}$ em junho.

O modelo VBHN240SJ25 da Panasonic mostrou resultados semelhantes ao modelo anterior, tanto na sazonalidade da produção como nas diferenças de produção ao considerar os primeiros ou os últimos anos da série climática. Porém, 
sua produção foi menor, com junho sendo o mês menos produtivo (menor do que $2800 \mathrm{KWh} / \mathrm{mês}$ ).

Um estudo do impacto das mudanças climáticas na Europa, aplicando modelos climáticos para estimar a geração de energia fotovoltaica, mostrou que o setor fotovoltaico europeu não seria ameaçado negativamente pelas mudanças climáticas (JEREZ et al., 2015). Resultados similares foram encontrados no presente estudo com dados observados para a Mata Paraibana, onde as mudanças climáticas históricas observadas (1961-2014) não afetaram sigficativamente a produção de energia elétrica através de paíneis fotovoltaicos.

TABELA 2. Produção de energia elétrica utilizando 100 unidades de painéis fotovoltaicos da AXITEC modelo AC-270P/156$60 S$ para a mesorregião da Mata Paraibana.

\begin{tabular}{lccc}
\hline \multicolumn{1}{c}{ Período } & $\begin{array}{c}\text { Primeiros } \\
\text { 10 anos }\end{array}$ & $\begin{array}{c}\text { Últimos } \\
\text { 10 anos }\end{array}$ & $\begin{array}{c}\text { Série } \\
\text { completa dos } \\
\text { dados }\end{array}$ \\
\hline Janeiro (kWh/mês) & 3969 & 3955 & 3961 \\
Fevereiro (kWh/mês) & 3820 & 3801 & 3808 \\
Março (kWh/mês) & 4088 & 4059 & 4070 \\
Abril (kWh/mês) & 3637 & 3617 & 3627 \\
Maio (kWh/mês) & 3816 & 3802 & 3805 \\
Junho (kWh/mês) & 3136 & 3130 & 3132 \\
Julho (kWh/mês) & 3480 & 3468 & 3471 \\
Agosto (kWh/mês) & 4056 & 4044 & 4045 \\
Setembro (kWh/mês) & 4104 & 4091 & 4091 \\
Outubro (kWh/mês) & 4752 & 4730 & 4734 \\
Novembro (kWh/mês) & 4728 & 4709 & 4712 \\
Dezembro (kWh/mês) & 4690 & 4670 & 4673 \\
Anual (kWh/ano) & $\mathbf{4 8 . 2 7 7}$ & $\mathbf{4 8 . 0 7 7}$ & $\mathbf{4 8 . 1 3 0}$ \\
\hline
\end{tabular}

TABELA 3. Produção de energia elétrica utilizando 100 unidades de painéis fotovoltaicos da Panasonic modelo VBHN240SJ25 para a mesorregião da Mata Paraibana.

\begin{tabular}{lccc}
\hline \multicolumn{1}{c}{ Período } & $\begin{array}{c}\text { Primeiros } \\
\mathbf{1 0} \text { anos }\end{array}$ & $\begin{array}{c}\text { Últimos } \\
\mathbf{1 0} \text { anos }\end{array}$ & $\begin{array}{c}\text { Série } \\
\text { completa dos } \\
\text { dados }\end{array}$ \\
\hline Janeiro (kWh/mês) & 3540 & 3527 & 3532 \\
Fevereiro (kWh/mês) & 3407 & 3389 & 3396 \\
Março (kWh/mês) & 3645 & 3620 & 3630 \\
Abril (kWh/mês) & 3244 & 3226 & 3235 \\
Maio (kWh/mês) & 3404 & 3390 & 3393 \\
Junho (kWh/mês) & 2797 & 2791 & 2793 \\
Julho (kWh/mês) & 3103 & 3093 & 3095 \\
Agosto (kWh/mês) & 3617 & 3606 & 3607 \\
Setembro (kWh/mês) & 3660 & 3648 & 3648 \\
Outubro (kWh/mês) & 4238 & 4218 & 4222 \\
Novembro (kWh/mês) & 4216 & 4199 & 4202 \\
Dezembro (kWh/mês) & 4183 & 4165 & 4167 \\
Anual (kWh/ano) & $\mathbf{4 3 . 0 5 3}$ & $\mathbf{4 2 . 8 7 4}$ & $\mathbf{4 2 . 9 2 2}$ \\
\hline
\end{tabular}


Segundo Hecktheuer (2001), a equação característica de uma célula fotovoltaica e a corrente de saturação reversa dependem da temperatura elevada ao cubo e da exponencial negativa do inverso da temperatura. A tensão de circuito aberto varia de forma linear com a temperatura. Assim, com o aumento da temperatura da célula a tensão de circuito aberto irá sofrer uma diminuição devido ao aumento da corrente de saturação (GASPARIN, 2009).

Gasparin (2009) realizou dois testes para analisar o comportamento da corrente e tensão de módulos fotovoltaicos. A primeira avaliação foi realizada mantendo a temperatura constante e divergindo a irradiância. Assim, quanto maior a irradiância, maior o valor de corrente com a tensão variando pouco. A segunda avaliação foi realizada mantendo a irradiância constante e divergindo a temperatura. Dessa forma, a corrente teve um aumento mínimo e a tensão do módulo teve uma diminuição pequena. Foi possível observar que as variações da corrente e da tensão foram maiores com o aumento da irradiância do que com o aumento da temperatura, resultados similares aos observados no presente estudo.

A produção fotovoltaica também foi analisada por Crook et al. (2011) para Europa, China, Argélia, Austrália, Estados Unidos e Arábia Saudita sobre como as mudanças projetadas de temperatura e insolação afetarão a sua produtividade. Os dados climáticos projetados foram obtidos a partir de modelos climáticos sob o cenário de emissões A1B do IPCC. Os resultados indicaram que há uma variação considerável na projeção da produção de eletricidade solar fotovoltaica, dependendo da localização e que no período entre 2010 e 2080 aumentará para a Espanha, Alemanha e China, havendo pouca alteração para a Argélia e a Austrália, e diminuirá no oeste dos Estados Unidos e na Arábia Saudita. Os autores afirmam também que além da temperatura e da insolação, outras variáveis climáticas também podem interferir positiva ou negativamente na produção fotovoltaica, como o vento, o índice pluviométrico, nebulosidade e a ocorrência de eventos extremos.

Alguns autores como Schaeffer et al. (2012) afirmam que alterações nos padrões de precipitação, insolação e temperatura podem afetar o setor energético em toda a sua cadeia, isto é, desde a produção até a sua utilização, introduzindo novas considerações e incertezas no gerenciamento de riscos e vulnerabilidades.

\section{CONCLUSÃO}

Foram realizadas análises de tendências climáticas para a mesorregião da Mata Paraibana, e estimada a produção de energia elétrica utilizando energia solar através da seleção de dois painéis fotovoltaicos. Tendências expressivas foram observadas para aumentos na temperatura do ar (temperatura máxima, média e mínima) no período analisado. Também foi observado um leve decréscimo na produção de eletricidade, causado pelo aumento da temperatura do ar. As tendências nos valores de nebulosidade não foram tão relevantes, contudo, qualquer alteração na nebulosidade poderia alterar significativamente a irradiação solar que chega aos painéis, afetando assim a produção fotovoltaica.

A mesorregião estudada possui alto potencial solar e vários projetos para estabelecimento de novos parques solares que podem auxiliar na diversificação da matriz energética da região e do Brasil. Os resultados deste estudo sugerem que, até o momento, os significativos incrementos na temperatura do ar tiveram pouca influência na produção de eletricidade através desses dois tipos de painéis. 


\section{AGRADECIMENTOS}

Os autores agradecem o apoio do Conselho Nacional de Desenvolvimento Científico e Tecnológico - CNPq (Projetos 305419/2015-3 e 401687/2016-3).

\section{REFERÊNCIAS}

AKHSASSI, M.; EL FATHI, A.; ERRAISSI, N.; AARICH, N.; BENNOUNA, A.; RAOUFI, M.; OUTZOURHIT, A. Experimental investigation and modeling of the thermal behavior of a solar PV module. Solar Energy Materials and Solar Cells, v. 180, n. 1, p. 271-279, 2018. Disponível em: <https://doi.org/10.1016/j.solmat.2017.06.052>. doi: 10.1016/j.solmat.2017.06.052.

AXITEC. AXI power: $\mathbf{6 0}$ células policristalino, 2016. Disponível em: $<$ http://www.axitecsolar.com/pt/modulos-solares.html>.

BRASIL - Ministério de Minas e Energia. Balanço Energético Nacional 2016: Ano base 2015 / Empresa de Pesquisa Energética. - Rio de Janeiro: EPE, 2016. Disponível em: <https://ben.epe.gov.br/BENRelatorioFinal.aspx?anoColeta $=2016$ \& anoFim Coleta=2015> Acessado em: 02/04/2018.

CARVALHO, M.; DELGADO, D. Potential of photovoltaic solar energy to reduce the carbon footprint of the Brazilian electricity matrix. LALCA- Revista Latino Americana em Avaliação do Ciclo de Vida, v. 1, N. 1, p. 64-85, 2017.

CONTI, J. B. Considerações sobre as mudanças climáticas globais. Revista do Departamento de Geografia, v. 16, p. 70-75, 2005.

CROOK, J. A.; JONES, L. A.; FORSTER, P. M.; CROOK, R. Climate change impacts on future photovoltaic and concentrated solar power energy output. Energy \& Environmental Science, v. 4, n. 9, p. 3101-3109, 2011.

DJAMAN, K.; BALDE, A. B.; RUDNICK, D. R.; NDIAYE, O.; IRMAK, S. Long-term trend analysis in climate variables and agricultural adaptation strategies to climate change in the Senegal River Basin. International journal of climatology, v. 37, n. 6, p. 2873-2888, 2016. Disponível em: <https://doi.org/10.1002/joc.4885>. doi: 10.1002/joc.4885.

FOLEY, A.; OLABI, A. G. Renewable energy technology developments, trends and policy implications that can underpin the drive for global climate change. Renewable and Sustainable Energy Reviews, v. 68, n. 2, p. 1112-1114, 2017. Disponível em: <https://doi.org/10.1016/j.rser.2016.12.065>. doi: 10.1016/j.rser.2016.12.065.

GASPARIN, F. P. Desenvolvimento de um Traçador de Curvas Características de Módulos Fotovoltaicos. Dissertação de Mestrado. Universidade Federal do Rio Grande do Sul. Porto Alegre, 2009.

GIRVETZ, E. H.; ZGANJAR, C.; RABER, G. T.; MAURER, E. P.; KAREIVA, P. Applied climate-change analysis: the climate wizard tool. PLoS One, v. 12, n. 4, 2009. Disponível em: <https://doi.org/10.1371/journal.pone.0008320>. doi: 10.1371/journalpone0008320. 
HECKTHEUER, L. A. Análise de associações de módulos fotovoltaicos. Tese de Doutorado. Universidade Federal do Rio Grande do Sul. Porto Alegre, 2001.

IBGE - Instituto Brasileiro de Geografia e Estatística. Resultados do Universo do Censo Demográfico 2010. Disponível em: < http://cidades.ibge.gov.br/xtras/perfil.php?lang=\&codmun=250750\&search=||infogr \%E1ficos:-informa\%E7\%F5es-completas > Acessado em: 10/08/2017

IPCC - Intergovernmental Panel in Climate Change. Impacts, Adaptation, and Vulnerability. Contribution of Working Group II to the Fifth Assessment Report of the Intergovernmental Panel on Climate Change. Edited by C. B. Field et al. Cambridge/New York, Cambridge University Press/IPCC, 2014.

JEREZ, S.; TOBIN, I.; VAUTARD, R.; MONTÁVEZ, J. P.; ROMERO, J.M.L. et al. The impact of climate change on photovoltaic power generation in Europe. Nature communications, $\quad$ v. $6, \quad$ p. 10014 , 2015. Disponível em: <https://doi.org/10.1038/ncomms10014>. doi:10.1038/ncomms10014.

MARENGO, J. A.; CAMARGO, C. C. Surface air temperature trends in Southern Brazil for 1960-2002. International Journal of Climatology, v. 28, n. 7, p. 893-904, 2007. Disponível em: <https://doi.org/10.1002/joc.1584>. doi:10.1002/joc.1584.

MENDONÇA, F.; DANNI-OLIVEIRA, I. M. Climatologia: noções básicas e climas do Brasil. $1^{\text {a }}$ ed. São Paulo: Oficina de Textos, 2007.

NOTTON, G.; CRISTOFARI, C.; MATTEI, M.; POGGI, P. Modelling of a double-glass photovoltaic module using finite differences. Applied Thermal Engineering, v. 25, n. 17, p. 2854-2877, 2005. Disponível em: <https://doi.org/10.1016/ j.applthermaleng . 2005.02.008>. doi: 10.1016/j.applthermaleng.2005.02.008.

PANASONIC. Photovoltaic module HIT - VBHN245SJ25 / VBHN240SJ25, 2017. Disponível em: <https://eu-solar.panasonic.net/cps/rde/xbcr/solar_en/VBHN240_ 245SJ25_EN.pdf>.

PORTAL BRASIL, 2014. Disponível em: <http://www.brasil.gov.br/meioambiente/2010/11/matriz-energetica>. Acessado em: 04/07/2017.

ROMANO, G. Segurança Energética e Mudanças Climáticas na União Europeia. Contexto Internacional, v. 36, n. 1, p. 113, 2014. Disponível em: <http://dx.doi.org/10.1590/S0102-85292014000100004>. doi: 10.1590/S010285292014000100004.

SALMI, T., MAATA, A., ANTILLA, P., RUOHO-AIROLA, T., AMNELL, T. Detecting trends of annual values of atmospheric pollutants by the Mann-Kendall test and Sen's slope estimates - the Excel template application Makesens. Finnish Meteorological Institute, Helsinki, Finland, 2002.

SANTIAGO, I.; TRILLO-MONTERO, D.; MORENO-GARCIA, I.M.; PALLARÉSLÓPEZ, V.; LUNA-RODRÍGUEZ, J. J. Modeling of photovoltaic cell temperature losses: A review and a practice case in South Spain. Renewable and Sustainable 
Energy Reviews, v. 90, n. 1, p. 70-89, 2018. Disponível em: <https://doi.org/10.1016/j.rser.2018.03.054>. doi: 10.1016/j.rser.2018.03.054.

SCHAEFFER, R.; SZKLO, A. S.; LUCENA, A. F. P.; BORBA, B. S. M. C.; NOGUEIRA, L. P. P.; FLEMING, F. P.; BOULAHYA, M. S. Energy sector vulnerability to climate change: a review. Energy, v. 38, n. 1, p. 1-12, 2012.

SIQUEIRA, C. D. Regime internacional de mudanças climáticas e segurança energética. Mediações-Revista de Ciências Sociais, v. 16, n. 2, p. 210-227, 2011. Disponível em: <http://dx.doi.org/10.5433/2176-6665.2011v16n2p210>. doi: 10.5433/2176-6665.2011v16n2p210. 